\title{
Formação docente e o ensino de Libras por meio de redes sociais
}

\section{Teacher training and Libras education through social networks ${ }^{1}$}

\author{
Raquel Rosan Christino Gitahy ${ }^{2}$ \\ Adriana Aparecida De Lima Terçariol ${ }^{3}$ \\ Mariane Della Coletta Savioli ${ }^{4}$
}

\section{Resumo}

O objetivo da pesquisa foi compreender como, a partir das interações por meio da rede social Facebook, os docentes discutem o ensino da Língua Brasileira de Sinais para o aperfeiçoamento da sua prática educativa inclusiva. Para embasar teoricamente foram usados os autores Vasconcellos; Pimentel; Nóvoa; Moran; Baranauska; Martins; Valente; Prado; Almeida; Goldfeld; Masetto e Behrens. A metodologia de pesquisa foi qualitativa envolvendo 32 docentes cursistas de um curso de extensão de Libras a formadora. Para a coleta de dados foram utilizados documentos das interações dos participantes na rede social Facebook. A análise dos resultados foi realizada a partir da

\footnotetext{
${ }^{1}$ Pesquisa financiada pelo Programa de Suporte à Pós-Graduação de Instituições de Ensino Particulares (PROSUP-CAPES).

2 Doutora em Educação. Pedagoga. Bacharel em Direito. Docente do Mestrado em Educação da Universidade do Oeste Paulista e da graduação da Universidade Estadual do Mato Grosso do Sul

3 Doutora em Educação e Currículo pela PUC/SP. Mestre e Pedagoga pela Faculdade de Ciências e Tecnologia Unesp/Campus de Presidente Prudente/SP. Atualmente é docente no Curso de Pedagogia e Programas de Pós-Graduação em Educação, vinculados à Universidade Nove de Julho (UNINOVE-SP). Integra a linha de Pesquisa Educação Popular e Culturas (LIPECULT) e Linha de Pesquisa e de Intervenção e Gestão Educacional (LIPIGES). Pesquisadora no Grupo de Estudos e Pesquisas em Educação, Currículo e Tecnologias GEPECeT (CNPq/UNOESTE/SP) e Líder do Grupo de Pesquisa em Educação, Tecnologias e Cultura Digital GRUPETeC (CNPq/UNINOVE/SP)

${ }^{4}$ Mestre em Educação pela Unoeste. Professora Especialista em Atendimento Educacional Especializado (AEE) na Prefeitura Municipal de Araçatuba. Docente da Fundação Municipal de Birigui - Faculdade de Ciências e Tecnologia de Birigui - FATEB. Possui Especializações em Educação Especial Inclusiva, AEE (Unesp / Marília), LIBRAS (UCP), e Didática Educacional (Universidade São Luis).
} 
Formação docente e o ensino de Libras...

leitura flutuante dos dados e o cruzamento entre a teoria, gerando a organização dos dados em dois eixos, a saber: eixo 1: Libras e o nível fonológico

e eixo 2: Libras e o bilinguismo. Os resultados evidenciaram a aprendizagem colaborativa entre os envolvidos no curso de formação, despertando em cada um dos participantes o interesse em transformar sua prática pedagógica, tornando-a mais inclusiva. A experiência obtida por meio desta pesquisa, permitiu-nos concluir que é realmente possivel propor uma formação aos professores em Libras usando a rede social como espaço formativo.

Palavras-chave: formação docente. Rede social. Facebook. Libras.

\section{Abstract}

The objective of the research was to understand how, through interactions through social network Facebook, teachers discuss the teaching of Brazilian Sign Language to improve their inclusive educational practice. To theoretically support the authors Vasconcellos; Pimentel; Nóvoa; Moran; Baranauska; Martins; Valente; Prado; Almeida; Goldfeld; Masetto and Behrens. The research methodology was qualitative involving 32 lecturers of Libras Fateb 2015 Extension Course and the teacher. In the data collection procedure, documents of the participants' interactions in social networks were used. The analysis of the results was performed from the fluctuating reading of the data and the crossing between the theory, generating the organization of the data from two axes, namely: axis 1: Libras and the phonological level and axis 2: Libras and bilingualism. The results showed collaborative learning among those involved in the training course, arousing in each of the participants the interest in transforming their pedagogical practice, making it more inclusive. The experience gained through this research has allowed us to conclude that it is really possible to propose teacher education in Libras using the social network as a formative space.

Keywords: Teacher Education. Social Network. Facebook, Libras 
Raquel Rosan Christino Gitahy, Adriana Aparecida De Lima Terçariol e

Mariane Della Coletta Savioli

\section{Introdução}

Compreendendo o processo e as transformações educacionais quanto às práticas pedagógicas, principalmente na inclusão de alunos com deficiências, vislumbramos um longo caminho percorrido na luta para a conquista de direitos políticos, sociais, civil e educacionais. Vasconcellos (1996) assevera como ocorre a luta na área educacional.

a) É um longo caminho; no entanto, se o primeiro passo não for dado... Passos pequenos, mas concretos, coletivos e na direção estabelecida.

b) A mudança de horizonte pode ser radical, qual seja, pode mudar substancialmente já. No entanto, a mudança da prática, vem aos poucos, não porque assim desejemos, mas por não conseguirmos mudar de uma vez. Numa fase de mudança é normal termos práticas novas mescladas com arcaicas. Ter clareza de que não se trata de ecletismo, "colcha de retalhos": a questão é saber para onde se quer ir e manter a tensão superadora. Alimentar a impaciente paciência histórica (VASCONCELLOS, 1996, p. 63-64).

Vasconcellos (1996) afirma que, nesse processo, não se deve esquecer de aprender com os erros, e também que a construção do conhecimento deve ocorrer por parte de todos. Assim, a fim de que a transformação educacional ocorra, vale ressaltar que:

d) $\mathrm{O}$ acúmulo de pequenas práticas transformadoras prepara para $\mathrm{o}$ salto qualitativo.

e) A implantação das mudanças da proposta pedagógica deve ser gradativa e envolver também as estruturas administrativas e comunitária da escola. É fundamental valorizar as iniciativas inovadoras que já estão acontecendo; além de revelarem possibilidades concretas, ajudam a diminuir as resistências e a passividade do grupo.

f) O espaço de reflexão coletiva e constante sobre a prática é fundamental para articulação do trabalho transformador. (VASCONCELLOS, 1996, p. 64).

Os docentes, buscando a transformação acima descrita, incitarão maior envolvimento dos alunos, que se sentirão mais próximos dos professores e mais envolvidos pelo conteúdo e pela metodologia. Para Pimentel (1996, p. 18), os alunos valorizam professores que: 
Formação docente e o ensino de Libras...

[... Estabelecem relacionamentos onde o formal e o informal, a firmeza e a tolerância, a autoridade e a liberdade não se apresentam com aspectos mutuamente excludentes, mas se constituem em atitudes geradoras de confiança mútua, estabelecidas a partir de projetos de trabalho ou de objetivos comuns de disciplina e cursos (PIMENTEL, 1996, p. 18).

Pimentel (1996) salienta que há professores preocupados em contemplar as expectativas dos alunos, esses possuem os seguintes perfis:

- ter uma mente aberta para questões críticas, problemas, especulações, teorias;

- ter conhecimentos necessários à vida profissional e poder buscálos onde quer que se possa encontrá-los;

- ter possibilidades de avaliar a realidade num ambiente diferentemente do escolar;

- mudar, transformar, reformular valores, crescer, amadurecer.

(PIMENTEL, 1996, p. 18).

Mas no que se refere às mudanças de práticas educacionais, os professores encontram obstáculos. Sobre o assunto, Nóvoa (1998) assegura, com relação às inovações escolares e educacionais envoltas numa prática reflexiva:

\begin{abstract}
A medida que os professores tentam criar condições para uma prática reflexiva, é muito possivel que se venham a confrontar com a burocracia escolar. A experiência dos professores que seguiram até ao fim o Teacher Project é muito elucidativa, ainda que deprimente. Um deles disse: Vou deixar a minha escola. O que aprendi aqui é demasiado bom para ela. Um outro afirmou: vou tentar criar uma aula aberta, uma escola alternativa. Sentiam-se ambos frustrados pela resistência oferecida pela escola relativamente às iniciativas que davam razão aos alunos (NÓVOA, 1997, p. 86).
\end{abstract}

Também para desenvolver a discussão com relação à formação de professores, numa perspectiva do professor reflexivo, Pimenta e Ghedin (2006) sugerem a experiência de Sonald Schön, professor de Estados Urbanos no MIT (Instituto de Tecnologia de Massachusetts, EUA), até o ano de 1998, em que esse fez transformações relacionadas aos aspectos curriculares nos cursos de formação de profissionais.

Observando a prática de profissionais e valendo-se de seus estudos de filosofia, especialmente sobre John Dewey, propõe que a formação dos profissionais não mais se dê nos moldes de um currículo normativo que primeiro apresenta a ciência, depois a sua aplicação e por último Interfaces da Educ., Paranaíba, v.11, n.31, p. 525 - 549, 2020 
Raquel Rosan Christino Gitahy, Adriana Aparecida De Lima Terçariol e

Mariane Della Coletta Savioli

um estágio que supõe a aplicação pelos alunos dos conhecimentos técnicos-profissionais. O profissional assim formado, conforme análise de Schön, não consegue dar respostas às situações que emergem no dia-a-dia profissional, porque estas ultrapassam os conhecimentos elaborados pela ciência e as respostas técnicas que esta poderia oferecer ainda não estão formuladas (PIMENTA; GHEDIN, 2006, p. 19).

Vindo ao encontro da ideia acima exposta, Moran (2012) destaca a necessidade de haver transformações educacionais. Para o autor, para que a mudança ocorra, deve-se primar pelos eixos: "o conhecimento integrador e inovador; o desenvolvimento de autoestima/autoconhecimento; a formação do aluno-empreendedor; a construção do aluno-cidadão; o processo flexível e personalizado" (MORAN, 2012, p. 39). Entende-se, assim que a mudança educacional, principalmente objetivando obter bases na perspectiva inclusiva, não acontecerá de uma única vez, pois é necessário desencadear um processo de formação docente, política e social, que envolva novas práticas, metodologias e ambientes educacionais.

Nesse sentido, observando os desafios de inclusão, especificamente de alunos surdos, e refletindo a respeito de como capacitar professores e profissionais da área da Educação em relação ao ensino de Libras e a um trabalho pedagógico com alunos surdos, de forma que pudesse propiciar inclusão e acesso ao conhecimento com autonomia educacional, foram propostas alterações no projeto de Curso de Extensão de Libras, da Faculdade de Ciências e Tecnologia de Birigui (FATEB) com carga horária de 180 horas. O desenvolvimento de forma diferente dos anos anteriores, sendo 50\% presencial com frequência quinzenal e 50\% por meio de um grupo fechado na Rede Social Facebook, intitulado "Curso de extensão de Libras", fez com que os participantes discutissem e esclarecessem questões sobre o desenvolvimento educacional e social do aluno com surdez e o uso de Libras como língua e objeto de inclusão daquele nas escolas públicas regulares.

Nesse contexto, o objetivo geral da pesquisa foi compreender como, a partir das interações por meio da rede social Facebook, os docentes discutem sobre o ensino da Lingua Brasileira de Sinais para o aperfeiçoamento da sua prática educativa inclusiva. Para evidenciar os encaminhamentos da 
Formação docente e o ensino de Libras...

experiência aqui abordada, a partir desse objetivo, neste artigo retrata-se na sequência, de forma breve, o percurso metodológico adotado para a realização desta pesquisa, bem como apresentam-se algumas das percepções dos participantes, considerando dois eixos temáticos, a saber: "Eixo 1: Libras e o nível fonológico" e "Eixo 2: Libras e o bilinguismo".

\section{Percurso Metodológico}

A presente pesquisa adotou uma abordagem qualitativa. Minayo (2001, p. 21) afirma que a metodologia qualitativa realiza seu trabalho por meio do "universo de significados, motivos, aspirações, crenças, valores e atitudes, o que corresponde a um espaço mais profundo das relações, dos processos e dos fenômenos, e, portanto, não deverão ser reduzidos à operacionalização de variáveis".

Foram sujeitos de pesquisa 32 cursistas, profissionais envolvidos com a educação regular e que estavam em formação em serviço, participando do Curso de Extensão de Libras. Tais profissionais eram professores da Educação Infantil, professores do Ensino Fundamental de $1^{\circ}$ ao $5^{\circ}$ ano e de $6^{\circ}$ ao $9^{\circ}$ ano, professores do Ensino Médio, assim como coordenadores, estagiários, psicólogo, policiais do Proerd ${ }^{5}$, profissionais e estudantes de cursos de Pedagogia, surdos e demais profissionais que atuavam de forma direta e indireta com o ensino regular.

Como a pesquisa envolveu coleta de dados com sujeitos, a mesma foi cadastrada na Coordenadoria Central de Pesquisa (CCPq) da Universidade do Oeste Paulista, sob o número 2912, avaliada e aprovada pelo Comitê Assessor de Pesquisa Institucional (CAPI) e pelo Comitê de Ética em Pesquisa (CEP) da Universidade do Oeste Paulista, em 21 de dezembro de 2015. Também obteve aprovação Ética do CEP/CONEP da Plataforma Brasil, sob o número 50758415.7.0000.5515, em 16 de dezembro de 2015.

Os dados da pesquisa foram coletados por meio da análise documental das interações realizadas nos grupos por meio do Facebook. A análise dos

\footnotetext{
${ }^{5}$ Programa de educação preventiva ao uso de drogas, que tem por objetivo evitar que crianças e adolescentes iniciem o seu uso.
}

Interfaces da Educ., Paranaíba, v.11, n.31, p. 525 - 549, 2020 
Raquel Rosan Christino Gitahy, Adriana Aparecida De Lima Terçariol e Mariane Della Coletta Savioli

resultados foi realizada a partir da leitura flutuante dos dados e o cruzamento entre a teoria, gerando a organização dos dados a partir de dois eixos, a saber: "Eixo 1: Libras e o nível fonológico" e "Eixo 2: Libras e o bilinguismo". Sendo assim, a seguir são apresentados e discutidos alguns dos resultados obtidos com este estudo, adotando-se como parâmetro de análise tais eixos.

\section{Apresentação e Discussão dos Resultados}

Em relação ao "Eixo 1: Libras e o nivel fonológico", notou-se que os docentes cursistas puderam compreender como se formam as linguas de sinais, quais as variações referentes à gramática da Libras, refletindo o porquê é importante o educador conhecer o nível fonológico e por qual motivo deve aprender a Libras para comunicar-se com os alunos surdos. O tema é relevante, pois sem os conceitos e o conhecimento das variações linguísticas, o professor não poderá auxiliar e nem se comunicar, adequadamente, com o aluno surdo, dificultando a interação deste aluno com a sala de aula.

Para a discussão do tema, foi usado o ambiente Facebook e objetos educacionais acessiveis aos participantes surdos. Baranauska, Martins e Valente (2013, p. 116), garantem: “Mesmo os surdos oralizados sentem dificuldades em acompanhar legendas, preferindo o auxílio de imagens e

explicações em Libras". Pensando nisso, foram propostas videoaulas e recursos com janela de interpretação de Libras, como se observa na Figura 1:

Figura 1 - Abertura da vídeoaula, com "janela de interpretação de Libras". 
Formação docente e o ensino de Libras...

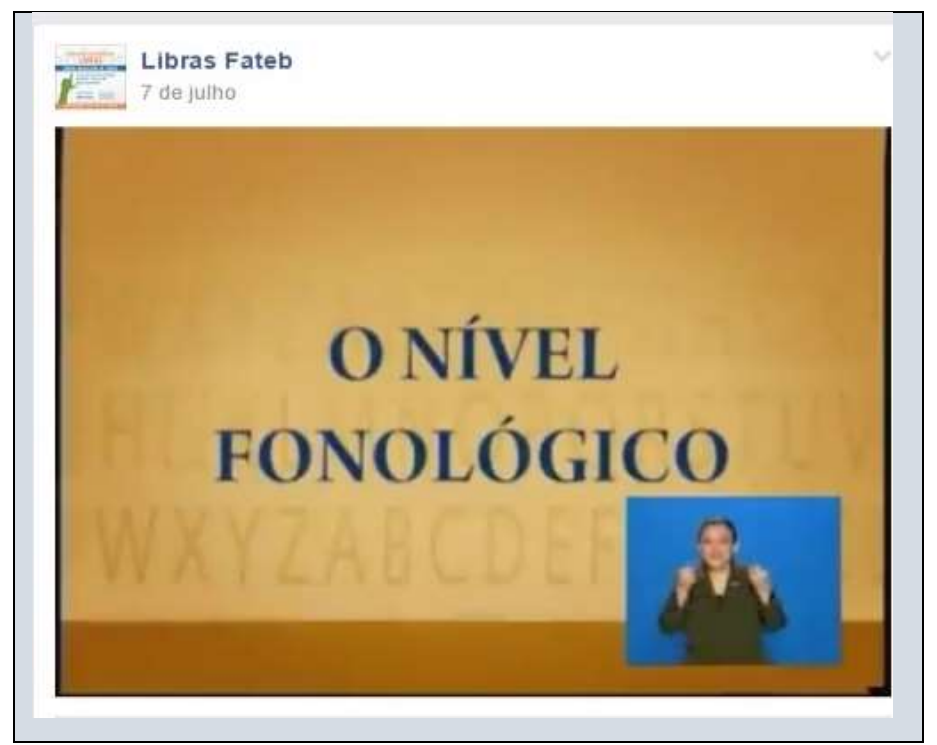

Fonte: Arquivo pessoal.

As videoaulas, durante a formação, exigiram a "janela de interpretação", pois parte dos cursistas participantes era composta por surdos, havendo a necessidade de adequações e estratégias acessiveis durante toda a formação. Assim, as videoaulas foram desenvolvidas em um ambiente inclusivo, possuindo toda a interpretação em Libras, permitindo a autonomia e interação de todos, conforme citam os autores abaixo.

\footnotetext{
Uma rede social - ou mesmo outros sistemas online - que carrega consigo a proposta de ser inclusiva, deve permitir a seus participantes interagir, expressando-se e comunicando-se por meio do sistema, de maneira autônoma e contínua. Para que isso ocorra, é importante que a RSI conte com um mecanismo de apoio que faça sentido para o público-alvo dessa rede e que seja acessivel em sua maior extensão possivel (BARANAUSKAS; MARTINS; VALENTE, 2013, p. 117).
}

Compreende-se, portanto, que o ambiente de formação, ou a rede social utilizada para este fim, e os objetos educacionais utilizados neste meio, devem propor condições de acessibilidade. Baranauska, Martins e Valente (2013, p. 117), consideram que "Outro desafio é a adequação às diferentes necessidades e habilidades dos usuários". A solução foi disponibilizar diferentes formatos de apresentação para um mesmo conteúdo (vídeos, imagens, áudio e vídeo com Libras).

É possivel visualizar na Figura 2 que, logo no início do debate, a formadora contextualizou o assunto, lançou um questionamento e um Interfaces da Educ., Paranaíba, v.11, n.31, p. 525 - 549, 2020 
Raquel Rosan Christino Gitahy, Adriana Aparecida De Lima Terçariol e Mariane Della Coletta Savioli

incentivo, afim de nortear e conduzir a reflexão durante o fórum de debate desse tema.

Figura 2 - Desenvolvimento do debate sobre Nível Fonológico.

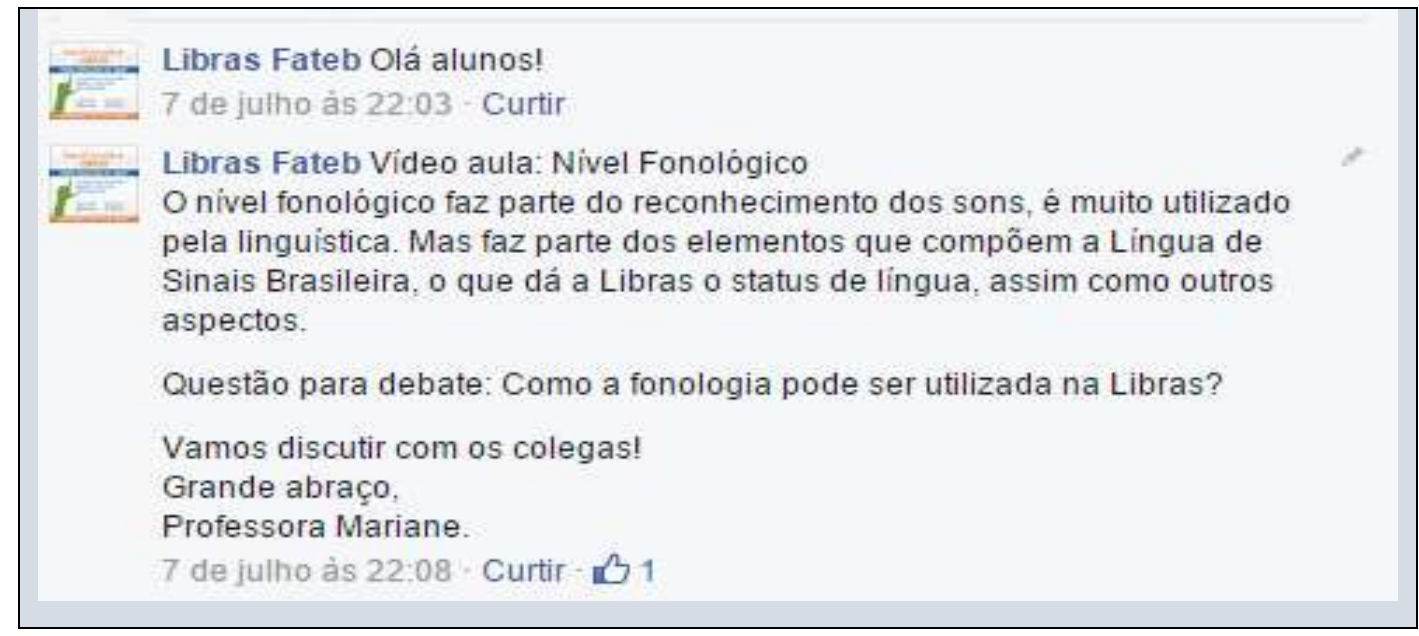

Fonte: Arquivo pessoal.

Sobre o envolvimento e as ações realizadas pela formadora no ambiente, observa-se as orientações de Valente, Prado e Almeida:

[...] pretendia-se provocar a tomada de consciência de que o papel do educador não é necessariamente o de provedor de informações, mas principalmente de orientador e parceiro na aprendizagem e novas descobertas, respeitando as idéias e estilos de trabalho dos alunos. Essa postura do docente-formador poderia ser referência para inspirar uma nova atitude do professor em formação com seus alunos (VALENTE; PRADO; ALMEIDA, 2003, p. 76).

Os participantes da formação, após assitirem a videoaula e realizarem a leitura do texto, desenvolveram uma breve relação dos pontos que consideraram mais importantes sobre o tema fonaudiologia e parâmetros linguísticos que compõem os sinais diante da Libras, e compartilham neste espaço que foi utilizado como um fórum de discussões.

Docente cursista A: Os fonemas são encontrados na Libras, à medida que essa lingua forma um número infinito de sinais a partir de cinco elementos, finitos: os parâmetros para a formação de sinais. Segundo os autores Quadros \& Karnop (2004) temos a configuração de mão (CM), o movimento da mão (M), a locação da mão (L), a orientação da mão (Or) $e$ as expressões não manuais (ENM).

Interfaces da Educ., Paranaíba, v.11, n.31, p. 525 - 549, 2020 
É possivel perceber que há interesse por parte dos participantes e que os mesmos entendem o Facebook como um espaço de compartilhamento de ideias e informações.

Docente cursista B: O nivel fonológico - estuda- características, aspectos morfológicos, semânticos e temáticos. Ex.: a criança vai descobrir a língua materna naturalmente, a criança não faz esforço $p$ entender a linguagem materna. Enquanto $q$ o Linguista se debruça sobre a lingua de seu interesse com ferramentas adequadas para explicar como é usado. No comportamento de um Linguista ele usa regras de estruturação da lingua estudada, com conhecimentos estruturados, quer dizer, como ele se organiza.

No comentário a seguir, pode-se perceber que a formadora promove um feedback para enaltecer e melhor orientar as respostas dos participantes.

Formadora: Parabéns pelo envolvimento com o assunto "Nivel
Fonológico", [...], vocês realmente expuseram a importância dos 5
parâmetros para a formação dos sinais e sistematização da Lingua de
Sinais. O quanto a configuração e propositura dos parâmetros: CM, M,
L, Or e ENM formam expressões e sinais, além de que a mudança ou
diferenciação de um desses parâmetros, trazem significados diferentes
no vocabulário linguístico da Libras. Bem lembrado, [...], quanto aos
traços distintivos, que no âmbito da comunicação, fornece elementos
que diferem as expressões de acordo com o contexto necessário. As
intenções e direcionamentos são bem propostos neste momento da
comunicaçâo. Importante relatar, que no ambiente de aprendizagem utilizado, no caso o Facebook, a formadoraque aparece neste momento como "Libras Fateb", realiza constantemente um feedback rápido para os participantes do curso. Isso promove uma participação contínua, incentivadora que motiva a cada momento o cursista a estudar e interagir ativamente.

O feedback que mediatiza aprendizagem é aquele colocado de forma clara, direta, por vezes orientando discursivamente, por vezes por meio de perguntas, ou de uma breve indicação ou sugestão. Justamente com o feedback contínuo, há que se desenvolver um registro de todos aprendizes, de forma pessoal e siténtica, mas que permita um diálogo e um acompanhamento sobre o processo de aprendizagem como um todo, e não apenas cada atividade isoladamente (MORAN; MASETTO; BEHRENS, 2000, p. 166).

Interfaces da Educ., Paranaíba, v.11, n.31, p. 525 - 549, 2020 
O Facebook, por ser de fácil acesso, envolve tanto os participantes e cursistas, quanto a formadora, pois pode ser conectado com rapidez de qualquer dispositivo móvel. Basta acessar a internet, que qualquer recado ou participação, comentário ou postagem no curso, realizado por colegas ou formadora, é indicado com um aviso instantâneo no dispositivo. Isso fez com que os participantes estivessem conectados e ativos de forma constante na formação.

O compartilhamento de curiosidades e informações adicionais aos temas, por meio do Facebook, pode ser verificada na resposta de uma participante, descrita abaixo:

\begin{abstract}
Docente cursista C: 'Fonologia na Libras mostra criação de como os sinais são formados, como usá-los, ensiná-los, etc.

Sei lá se pode, mas dei uma lida, achei que poderia postar.. Vê se este site é bom professora, eu achei interessante.

"Qual é a origem da profissão? A Fonoaudiologia é uma ciência estudada de forma sistemática nas universidades em mais de uma centena de paises do mundo e existe formalmente há mais de um século. A primeira referência formal é de 1900, quando a Hungria reconheceu a profissão e criou a primeira faculdade de Fonoaudiologia no mundo.

No Brasil, sua história é ainda mais antiga, se considerada a sua associação com a da Educação Especial. A primeira marca identificatória da profissão é da época do Império, com a criação, em 1854, do Imperial Colégio, voltado para meninos cegos (hoje, Instituto Benjamim Constant), seguido, no ano seguinte, com a criação do Colégio Nacional, destinado ao ensino dos deficientes auditivos. Em 1912, documentos comprovavam que a Fonoaudiologia já se diferenciava da educação especial, com o início de pesquisas específicas, relacionadas aos distúrbios da voz e da fala, e com a implantação de cursos de orientação a professores."

http://www.fonosp.org.br/.../o-que-e-a-fonoaudiologia/'
\end{abstract}

Isso motivou os demais participantes que reúnem seus conhecimentos e perspectivas durante o debate, o que pode ser observado na Figura 3 a seguir.

Figura 3 - Debate sobre o tema, após compartilhamento de informações dos próprios cursistas. 




Fonte: Arquivo pessoal.

A formadora, na Figura 3, realizou feedback para incentivar a contribuição do participante e insejar que as participações ocorressem realmente de forma colaborativa. Veja a seguir:

Formadora: Olá, é claro que pode postar! Você está compartilhando um Link muito interessante e responsável do Conselho Regional de Fonoaudiologia, e isso se chama aprendizagem colaborativa. É isso mesmo que quero de vocês. Espero que os colegas entrem e possam ler o site, pois é um site confiável e responsável. Parabéns pela colaboração. Continue realizando outras. Você traz argumentos interessantes quanto a diferença do profissional que trabalha com a fonoaudiologia e com o profissional pedagogo da educação especial, isso porque, como dizem "cada macaco no seu galho", ou seja, apesar dos profissionais da educação especial, habilitados no trabalho com o aluno com surdez, ter o dever de conhecer a importância da fonoaudilogia no desenvolvimento deste aluno e com o ela deve acontecer, não devem se aprofundar e se arriscar a realizar esse trabalho que é do fonoaudiólogo. O professor da Educação Especial, como o professor do Atendimento Educacional Especializado - AEE para $o$ aluno com surdez, deve realizar o atendimento em três diferentes momentos: O AEE de Libras, para ensinar a Lingua Brasileira de Sinais para o aluno surdo e em sala de aula para os colegas e professores aprenderem a Libras e depois se comunicarem com o colega surdo; $O$ AEE em Libras, que transforma o conteúdo escolar em recursos concretos e imagéticos, que com a interpretação da Libras, transpõe o conteúdo acadêmico de forma adequada ao aluno com surdez; e por fim o AEE em Lingua Portuguesa na modalidade escrita e leitura apenas,

Interfaces da Educ., Paranaíba, v.11, n.31, p. 525 - 549, 2020 


\section{Raquel Rosan Christino Gitahy, Adriana Aparecida De Lima Terçariol e Mariane Della Coletta Savioli}

para que o surdo possa estar incluido no universo letrado em que vivemos. Excelente pesquisa! Continue assim!.

\section{O feedback realizado pela formadora, incentiva e desafia os} participantes a estudarem e contribuirem com os debates. A seguir observase o feedback da formadora:

Docente cursista D: O Nivel Fonológico que trata da linguagem de sinais, fala sobre a importância dos 5 parâmetros que são: Configuração das mãos; Ponto de articulação ou locação; Movimento; Orientação e a Expressão facial e corporal. A configuração das mãos pelo que entendi é a principal que comanda os outros parâmetros. A Libras foi reconhecida e oficializada como a Lingua de Sinais e vem se aprimorando os estudos em torno do assunto, despertando o interesse dos que se preocupam em melhorar o convivio na comunidade escolar $e$ familiar dos surdos-mudos. Admiro minhas colegas de curso que são exemplos de dedicação e engajamento. Sinto muita dificuldade de acompanhar o ritmo de estudo no Facebook.

Docente cursista E: A fonologia é utilizada na formação dos sinais de libras baseando-se na combinação dos 5 parâmetros: Articulação de mãos (CM), ponto de articulação (PA), movimento (M), orientação $(O) e$ expressão facial e corporal (EFC). Pequenas diferenças nas configurações das mãos ou nos pontos de articulação podem produzir expressões totalmente diferentes, como o exemplo que foi dado: trauma $x$ responsável. Daí a importância de realizar os sinais da maneira mais eficiente possivel...

Formadora: A criança ao adquirir a lingua materna deve aprender os fonemas da sua lingua.

Os sons e imagens são recursos representacionais que são linguas orais e visuais utilizadas para comunicar e codificar imagens.

Os fonemas são encontrados na LIBRAS, essa lingua forma um número infinito de sinais que são as unidades minimas que formam os sinais, as combinações e as variações no ambiente fonológico.

As unidades minimas são: configuração de mãos, ponto de articulação ou localização da mão, movimento, orientação e aspectos não manuais dos sinais, essas unidades podem ocorrer de maneira simultânea e não consecutivas.

Os articuladores das linguas de sinais são as mãos, que se movimentam no espaço em frente ao corpo e articulam em determinadas localizações nesse espaço, os movimentos do corpo e da face também desempenham funções.

Formadora: Turma, apenas lembrando e esclarecendo alguns termos, pois essa é uma das minhas funções durante as discussões, certo. A LIBRAS é uma lingua oficial e reconhecida e não apenas uma linguagem, ou seja, não é somente uma expressão. Também, vamos lembrar que as pessoas com surdez, são chamadas hoje como SURDAS, esse é o termo correto, pois só não falam por não possuírem a audição. Mudas, são pessoas que na maioria das vezes possuem limitações $e$ deficiência nas cordas vocais ou na voz. Normalmente, pessoas mudas, nem sempre são surdas, tudo bem. Abraços e vamos continuar as nossas reflexões. 
Formação docente e o ensino de Libras...

O debate, ocorrido no Facebook, dos temas que refletiam sobre o uso da Libras, suas características e o ensino do aluno surdo, favoreceu o diálogo entre os participantes. No caso dos surdos, esses enviavam vídeos para participarem das discussões, e com isso, foi possivel verificar que o ambiente das redes sociais favoreceu além da agilidade nos debates, a acessibilidade, o que facilitou a interação entre os participantes. Durante as reflexões obtidas no debate, a formadora marca o nome dos participantes que ainda não haviam realizado suas reflexões (Figura 4). Após essa marcação, esses participantes visualizam a necessidade de participarem do diálogo, incitado pelo formador que acompanhava os estudantes em todos os contextos educacionais, reafirmando o pensamento abaixo citado.

\footnotetext{
Antes, o professor só se preocupava com o aluno em sala de aula. Agora, continua com o aluno no laboratório (organizando a pesquisa), na internet (atividades à distância e no acompanhamento das práticas, dos projetos, das experiências que ligam o aluno à realidade, à sua profissão 9no ponto entre a teoria e a prática) (MORAN, 2012, p. 94).
}

O debate torna-se, portanto, momento importante de aprendizagem colaborativa, pois além de somar os diferentes conhecimentos, conceitos e ideias de cada participante. Para que isso aconteça, o professor deve estar atento às participações dos alunos, afim de que todos estejam envolvidos na construção do conhecimento.

Figura 4 - participação no debate, após serem chamados pela formadora. 


\section{Mariane Della Coletta Savioli}

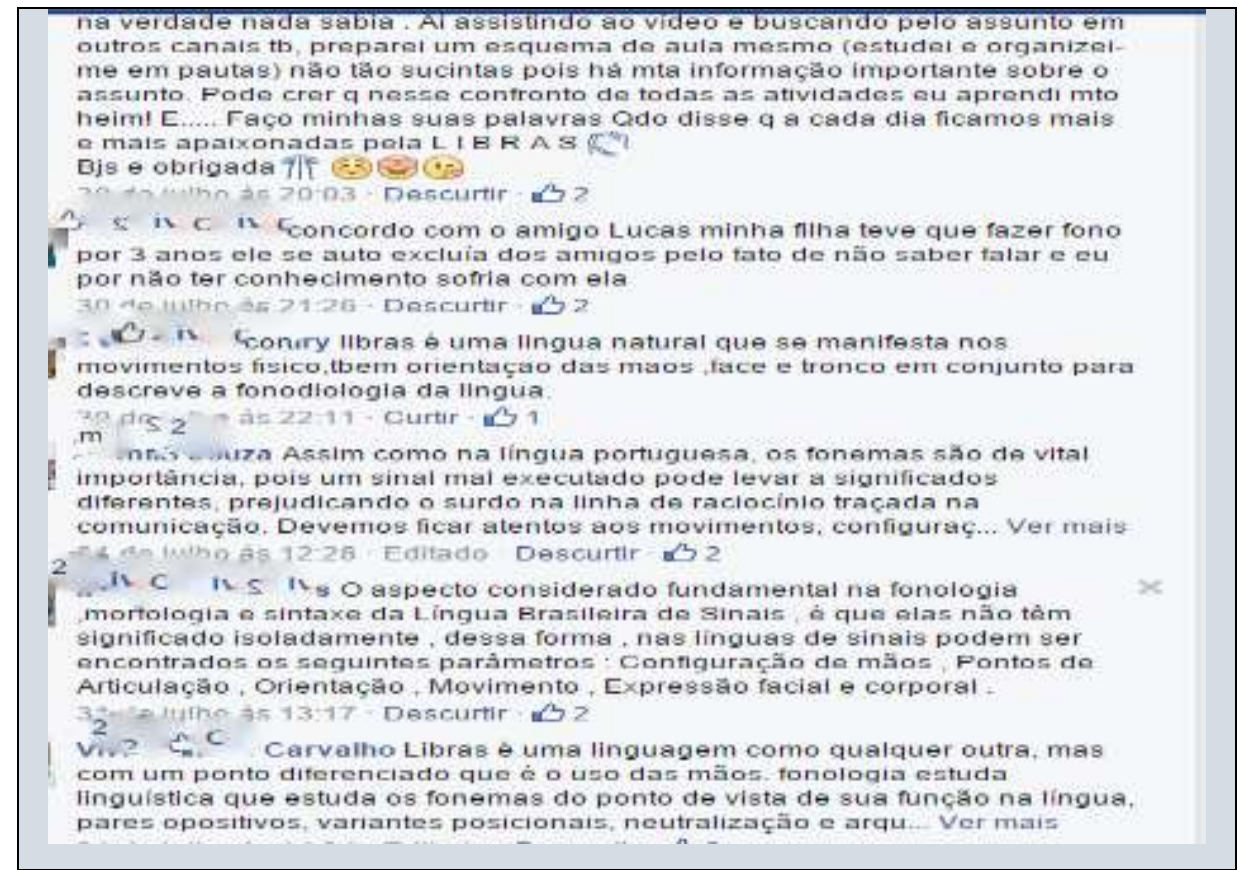

Fonte: Arquivo pessoal.

Serem "marcados" (expressão utilizada para chamar alguém ao debate no Facebook) pela formadora, no ambiente, não causou nenhuma estranheza ou intimidação por parte dos cursistas, pois já estavam aptos a lidar com esse formato de indicação realizado no Facebook, além de ter sido essa uma das instruções acontecidas, presencialmente, sobre o uso do Facebook durante a formação de Libras.

Antes, o professor se restringia ao espaço de sala de aula. Agora, precisa aprender a gerenciar também atividades à distância, realizar visitas técnicas, orientar projetos e, tudo isso, como parte da carga horária de sua disciplina, visível na grade curricular, flexibilizando o tempo que está em aula e incrementando outros espaços e tempo de aprendizagem (MORAN, 2012, p. 94).

Abaixo, na Figura 5, vemos um "post” realizado por um participante durante uma das discussões, com o objetivo de lembrar os demais participantes sobre como devem se referir às pessoas com deficiências.

Figura 5 - Finalização do debate sobre Nivel Fonológico. 
Formação docente e o ensino de Libras...

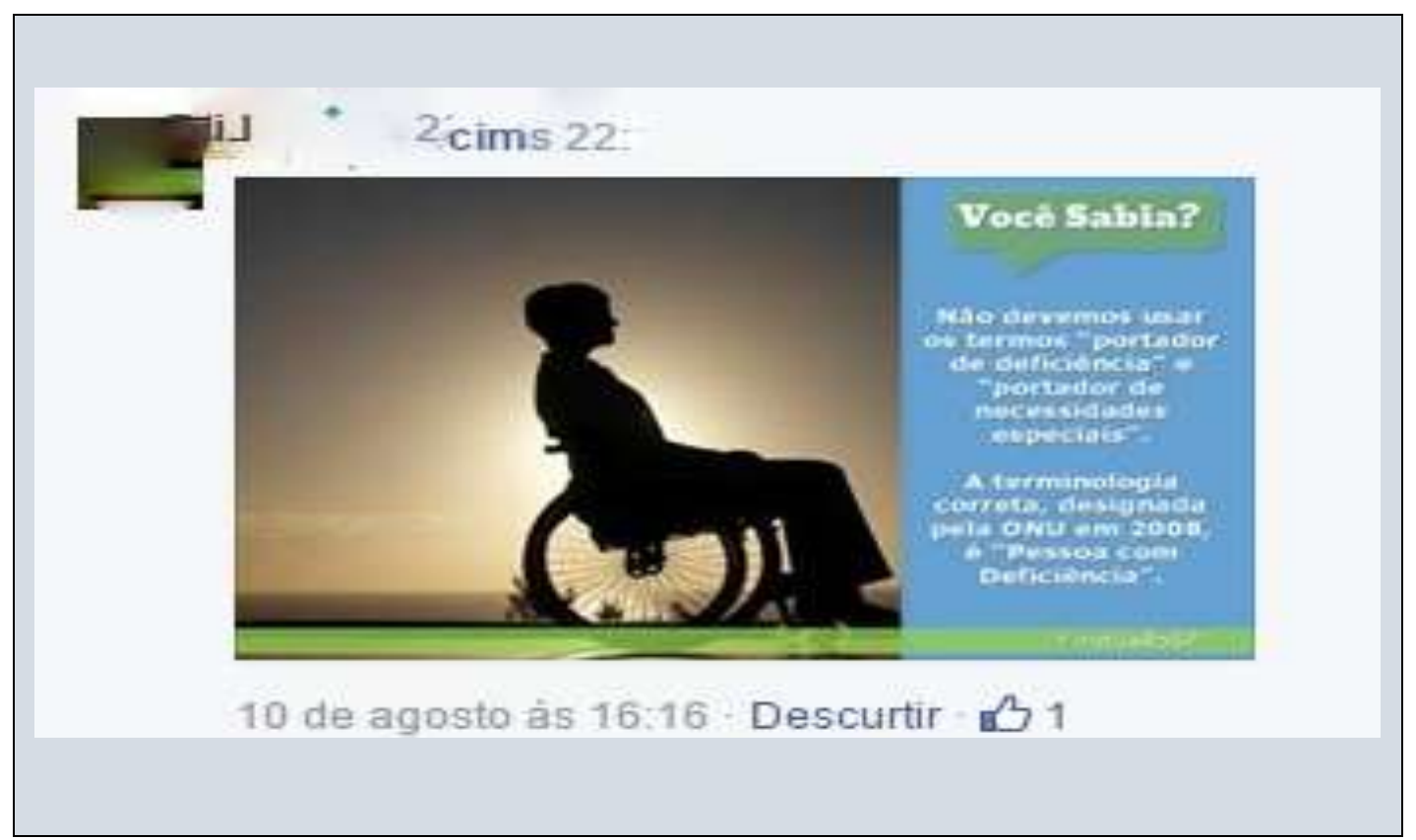

Fonte: Arquivo pessoal.

Em seguida, a formadora elogia e faz um incentivo sobre a necessidade de realizar o compartilhamento colaborativo, com o objetivo de construir o conhecimento.

Formadora: Obrigada pelo compartilhamento sobre as terminologias utilizadas para as pessoas com deficiências. Nós educadores e demais profissionais devemos estar atentos às terminologias adequadas para que não possamos por descuido ferir a integridade moral e ética de qualquer individuo. Muito bem! Beijos

Essa foi uma importante contribuição realizada pelo participante, pois utilizar corretamente as terminologias para chamar e referir-se às pessoas com deficiências, mostra respeito por estas pessoas.

Quanto ao "Eixo: Libras e o bilinguismo", cabe ressaltar inicialmente que o Bilinguismo é a abordagem atual tanto na comunicação quanto no aprendizado educacional do aluno com surdez. Por isso, neste momento da formação de Libras, os professores cursistas refletem - em um novo fórum de debate proposto no Facebook -, sobre compreender a importância do aluno que possui a surdez severa ou profunda, aprender a Libras como a primeira lingua, ou seja, a lingua materna e depois aprender a Lingua Portuguesa na modalidade de leitura e escrita. 
Raquel Rosan Christino Gitahy, Adriana Aparecida De Lima Terçariol e Mariane Della Coletta Savioli

O bilingüismo tem como pressuposto básico que o surdo deve ser bilíngue, ou seja, deve adquirir como língua materna a língua de sinais, que é considerada a língua natural dos surdos e, como segunda língua, a língua oficial do seu país. Os autores ligados ao bilinguismo percebem o surdo de forma bastante diferentes dos autores oralistas e da Comunicação Total. Para os bilingüistas, o surdo não precisa almejar uma vida semelhante ao ouvinte, podendo aceitar e assumir sua surdez (GOLDFELD, 2002, p. 42).

Entendia-se que o educador precisaria entender o bilinguismo, para que futuramente, pudesse ensinar ao seu aluno surdo por meio da Libras, mesmo que haja o intérprete em sala de aula regular. e deve conhecer como o surdo aprende a Língua Portuguesa, compreendendo as especificidades do ensino deste para o surdo, que pode variar de acordo com sua lingua materna, ou seja, de acordo com a Libras.

Veja a chamada (Figura 6) para o vídeo e debate realizados pela formadora:

Figura 6 - Videoaula sobre Bilinguismo com janela de interpretação em Libras.

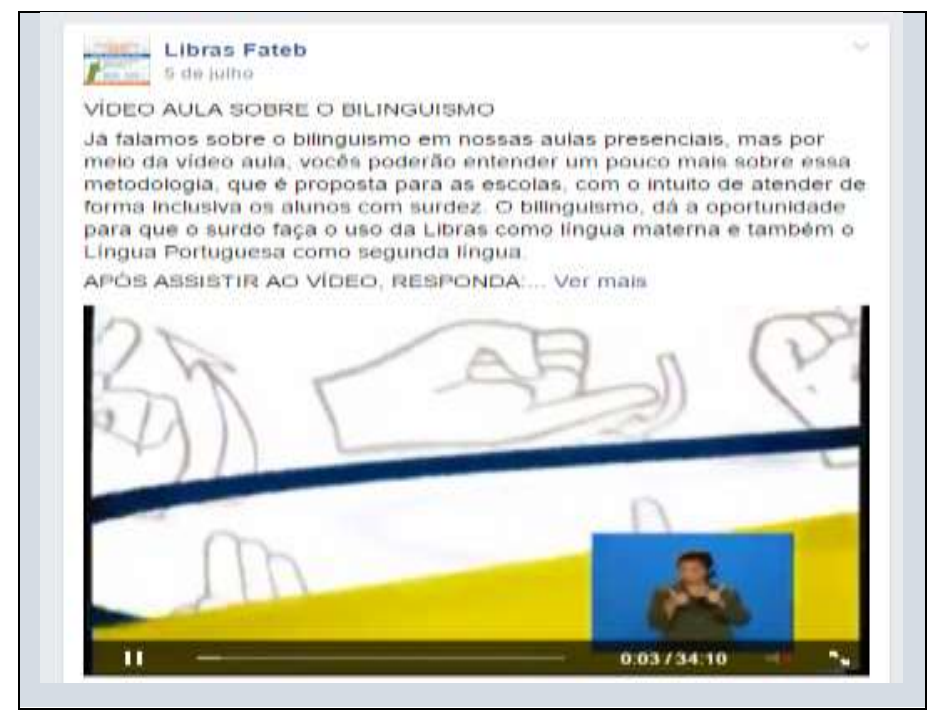

Fonte: Arquivo pessoal.

Formadora: APÓS ASSISTIR AO VÍDEO, RESPONDA:

Como pode ser o aprendizado do aluno surdo, diante da abordagem atual, o Bilinguismo numa educação inclusiva? 
Formação docente e o ensino de Libras...

Vamos assistir. Também já foram postados os textos. Abraços.

Valente, Prado e Almeida (2003) afirmam sobre a importância das discussões e de todo o conteúdo do curso na modalidade à distância, via internet, acontecer por meio de dinâmicas interativas, consignas reflexivas que possam estimular o interesse no debate, incentivando a criticidade e o compartilhamento de experiências. Assim,

A metodologia utilizada consistiu em estimular o pensamento dos professore-alunos, provocando a reflexão e respostas propositivas, que serviram de base para a interação, permitindo que o desenvolvimento do conteúdo se desse em função de suas respostas às provocações feitas pelo docente durante o processo de aprendizagem (VALENTE; PRADO; ALMEIDA, 2003, p. 168).

As discussões obtidas, a partir de uma consigna reflexiva, determinam a qualidade das informações e do incentivo gerado nas interações professoraluno e pela facilidade proporcionada em acesso ao ambiente do Facebook. Tais interações, obtidas por meio das interações professor-aluno, são verificadas nas discussões a seguir.

Docente cursista G: O ensinamento do aluno surdo deve ser através do Letramento, uma vez que esse tipo de aprendizado é visual, não havendo necessidade do conhecimento fonético das palavras (oralidade). Para isso há a necessidade de profissionais que tenham um perfeito conhecimento na área do ensino bilingue.

Docente cursista G: Importante também que a criança conviva com outros surdos para assimilar a cultura e estar sempre em contato com sua lingua natural.

Formadora: Ótima colocação Osmarina. Além do Letramento realizado por meio do ensino de profissionais especializados é fluentes, muito importante que a criança surda tenha contado com um surdo adulto de referência, para que ele possa se espelhar neste adulto, isso fará uma grande diferença em seu desenvolvimento. Abraços.

Docente cursista H: Pontos que eu gostei no vídeo: teoria de Vigotsky que diz que pra exteriorizarmos qualquer sinal primeiro precisamos interiorizar conceitos, gostei de aprender sobre o rota lexical e quando, no filme diz que crianças aprendem rápido já os adultos dependem de dedicação; ponto que eu não gostei : quando diz que médico trabalha com o que não funciona, isso não é verdade pois convivo com otorrino que trabalha com reabilitação auditiva e que dá a maior importância para a audição residual no sentido de estimular ao máximo e inclusive incentiva o aprendizado de libras....bom, ficam aqui as minhas considerações!! Bjos

Interfaces da Educ., Paranaíba, v.11, n.31, p. 525 - 549, 2020 
É possivel perceber, por meio das interações descritas, que os participantes da formação se envolveram com os temas, e após assistirem às videoaulas, argumentam de forma reflexiva suas ideias diante das questões norteadoras, propostas pela formadora.

Veja mais algumas das interações.

Docente cursista I: não podemos esquecer da importância da familia em conhecer a Libras para manter uma melhor comunicação com a criança surda, assim ela se sentira incluida no vinculo familiar.

Docente cursista J: A criança surda deve desde cedo conhecer a LIBRAS já que esta será sua língua materna e futuramente aprender a lingua portuguesa que será oferecida em horário diferenciado ao da classe comum em salas de recursos.

Vale ressaltar que para o surdo a Lingua de sinais é o meio de comunicação pois através dela é expresso pensamentos, sentimentos, da linguagem dos surdos.

O professor que está disposto a fazer um trabalho pedagógico eficaz deve se conhecer a lingua de sinais, para que consiga atingir os objetivos propostos e levar em consideração as necessidades e anseios.

Formadora: [...] Isso mesmo. A Libras deve ser aprendida pelo aluno surdo como a língua materna, ou seja, aquela que será sua verdadeira comunicação, fonte de expressão e conhecimento. A língua portuguesa deverá vir depois, como a segunda língua, na modalidade escrita e leitura apenas.

Verificou-se, portanto, o conhecimento que os educadores obtiveram com a formação. Conhecimento esse, também obtido por meio do debate colaborativo por meio do uso do Facebook, que proporciona maior interatividade e facilidade nas discussões.

A formadora realiza o feedback durante o debate assincrono ${ }^{6}$, sobre o Bilinguismo, como evidenciam os excertos a seguir.

Docente cursista $\mathrm{J}$ : O bilinguismo é um dos métodos que melhor favorece a educação dos surdos tendo em vista a lingua dos sinais como lingua materna e a lingua portuguesa como segunda, sendo oferecida em periodo contrário ao ensino regular.

A introdução da lingua de sinais na educação da criança surda deve ser iniciada o quanto antes mediante profissionais capacitados e o auxílio familiar, uma vez que é de vital importância o conhecimento da

\footnotetext{
${ }^{6}$ Que não se realiza ao mesmo tempo que outro. "assincrona", in Dicionário Priberam da Lingua Portuguesa [em linha], 20082013, https://www.priberam.pt/dlpo/ass\%C3\%ADncrona [consultado em 27-02-2017]. Interfaces da Educ., Paranaíba, v.11, n.31, p. 525 - 549, 2020
} 
Formação docente e o ensino de Libras...

língua pelos pais, evitando que sinais próprios adquiridos pela família possam interferir na formação educacional da criança.

Formadora: Muito bem. O Bilinguismo realmente é a abordagem educacional e comunicacional que mais auxilia no desenvolvimento do aluno surdo nos dias atuais, pois favorece a compreensão, o desenvolvimento intelectual, a interação e a inclusão do Estudante com surdez.

Boa parte dos alunos participa da reflexão sobre o tema em debate, pois esse é um dos grandes desafios enfrentados pelos professores nas escolas, ou seja, a importância de se utilizar a Língua de Sinais Brasileira e também ensinar a Língua Portuguesa como segunda língua aos alunos com surdez. O desafio, está ai, em como realizar este ensino, sendo a Língua de Sinais considerada a primeira língua ao surdo, pela facilidade de interação e uso, e a Língua Portuguesa como segunda língua, apenas na modalidade escrita, pela exigência de um mundo e de uma sociedade inteiramente letrada. Por meio da Língua de Sinais, tal desafio torna-se possível, entretanto, o professor e demais profissionais devem estar devidamente capacitados para este ensino.

Na Figura 7, a pedagoga surda, participante da formação, expõe seu parecer e suas reflexões sobre o Bilinguismo, possuindo propriedade e experiência própria, pois possui a surdez, tem boa fluência em Libras e faz uso da Língua Portuguesa, na modalidade escrita. Isso mostra o quanto o ambiente e seus objetos são acessiveis e também nos faz pensar na importância desta formação com a participação da pedagoga surda e demais cursistas surdos, que trocam experiências e vivências com professores e demais profissionais ouvintes.

Figura 7 - Continuação do debate sobre o Bilinguismo. 


\section{Mariane Della Coletta Savioli}

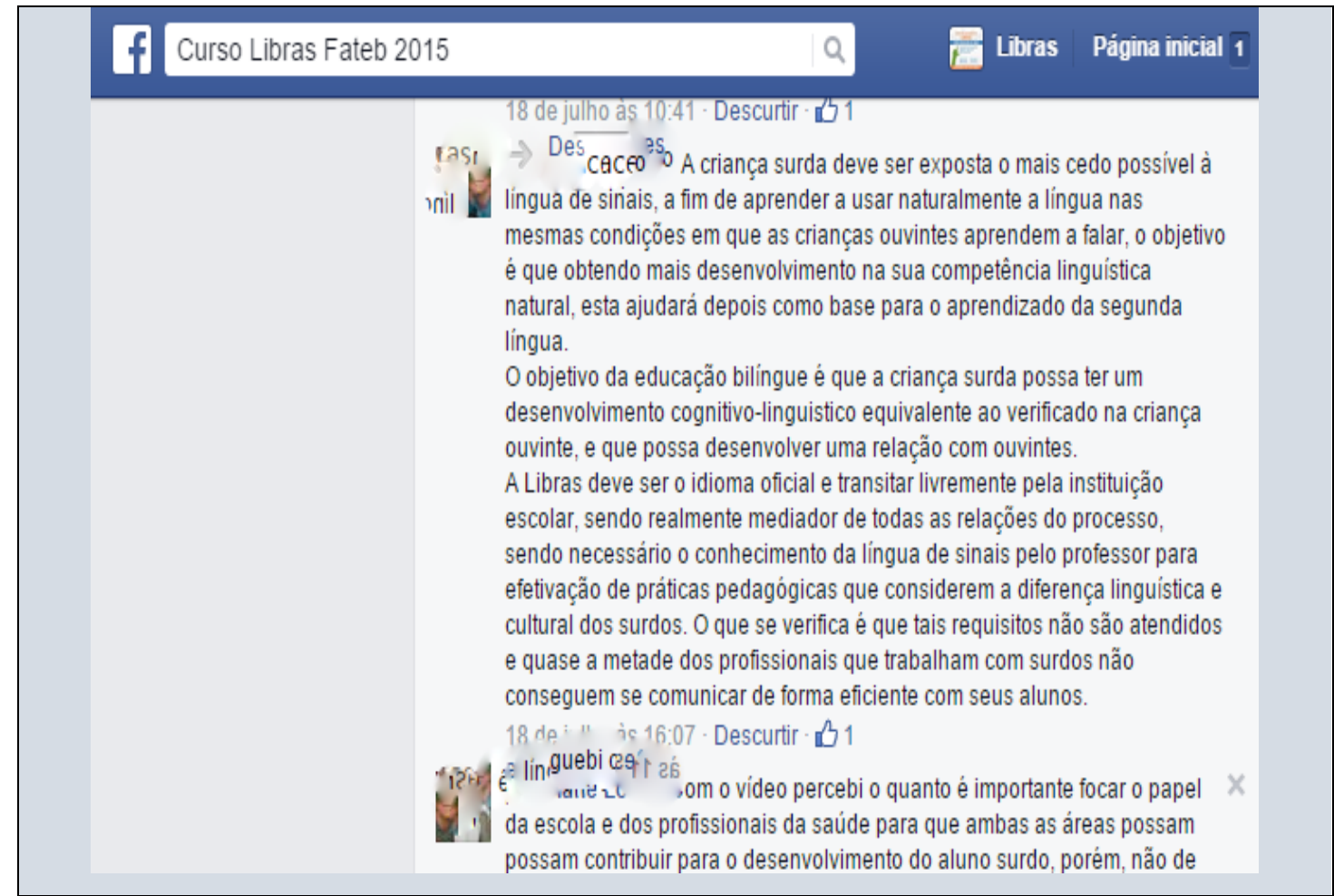

Fonte: Arquivo pessoal.

Segue mais um pouco do debate, em que a formadora realiza a tarefa de responder aos questionamentos e intervir, quando necessário, para orientar os cursistas. O feedback também é importante, e acontece com facilidade quando realizado no Facebook. A vantagem de acesso rápido e por meio de dispositivos móveis, torna a discussão ágil e pontual.

Docente cursista K: A escola deve estar preparada com profissionais qualificados e preparados para enfrentar barreiras e desafios e a família deve buscar informações, conhecer $e$ interagir com o aprendizado do seu filho e participar das dificuldades que virem a surgir tanto da escola quanto do aluno e "juntas", elaborar alternativas, pois, penso que a criança com deficiência precisa de um atendimento mais personalizado.

Formadora: Certamente! A criança com surdez, assim como qualquer aluno com deficiência, necessita $d$ e atendimentos especializados e por isso a familia e a escola, devem estar atentas e unidas para que essa criança obtenha um bom desenvolvimento e uma educação de qualidade. Muito bem!

Docente cursista L: Concordo com a Docente cursista K, de que é necessário profissional competente e dispostos a superar as barreiras, pois os desafios são muitos. Os pais precisam estar cientes de que depende deles a interação com a criança, que o amor que os unem thes dará forças para aprenderem a se comunicar, de uma maneira que

Interfaces da Educ., Paranaíba, v.11, n.31, p. 525 - 549, 2020 
Formação docente e o ensino de Libras...

facilite a compreensão e a assimilação do que se quer "falar" e do que está sendo "falado" pela criança. É muito complexo esse tema, pois na verdade, nós já falamos com nossos bebês através de palavras e sinais, desde que nascem até que adquiram a linguagem oral. A linguagem de sinais com valor (Libras) me assusta, pois percebo que preciso aprender muito ainda.

Docente cursista L: Concordo! Os profissionais que optarem por essa área específica devem estar ciente de que haverá muitas barreiras $e$ desafios a serem superados, assim como os pais que devem caminhar junto aos profissionais para alcançarem um objetivo único dentro do âmbito escolar e na sociedade. Acredito que num futuro não muito distante, essas barreiras deixarão de existir, pois todos nós estaremos engajados num mesmo propósito que é o convivio social sem preconceitos e tabus.

Formadora: Olá, isso mesmo, a língua de sinais deve ser ensinada e proposta para o surdo logo na primeira infância, juntamente com as primeiras estimulações, devendo fazer parte da vida do surdo logo no início, isso trará fluência em sua comunicação e facilitará o aprendizado da Língua Portuguesa na modalidade escrita, propondo uma educação que versa em torno da abordagem bilingue.

Formadora: Parabéns pela sua reflexão. É isso mesmo, a insuficiência do conhecimento da Libras por parte de professores e demais profissionais da educação, interferem no avanço cognitivo $e$ no aprendizado da criança surda, isso pois, para que a aprendizagem seja eficaz é necessário estabelecer uma comunicação bastante fluente. Essa fluência, depende do quanto o professor/educador está disposto a aprender para ensinar e comunicar-se com seu aluno surdo. Muitas vezes, o educador acredita que não é obrigação dele ensinar este aluno, preferindo ficar na zona de conforto ao invés de buscar uma comunicação com seu aluno. A falta de comunicação gera exclusão, o professor que não busca o conhecimento, torna a sua aula menos igualitária e de pouca qualidade.

A formadora expôs o quanto é necessário que os participantes e demais profissionais ligados à educação estejam atentos a esse olhar inclusivo, e com entusiasmo para aprender novos conhecimentos, assim como a Libras.

\section{Considerações Finais}

A experiência obtida por meio desta pesquisa, permitiu-nos concluir que é realmente possivel propor uma formação aos professores, no que se refere à Lingua Brasileira de Sinais, usando a rede social Facebook, como espaço formativo. Tal contexto já fazia parte do cotidiano dos professores e participantes surdos, e por isso houve facilidade em seu uso, o que proporcionou muitas participações. A partir das interações ocorridas nas redes sociais, os participantes obtiveram uma proximidade com a Língua 
Raquel Rosan Christino Gitahy, Adriana Aparecida De Lima Terçariol e Mariane Della Coletta Savioli

Brasileira de Sinais, com destaque as discussões do bilinguismo e nível fonológico, refletindo a formação docente para uma prática inclusiva.

O uso do Facebook como ambiente de formação foi efetivado neste estudo, uma vez que propiciou aos participantes discutirem sobre o ensino de Libras, de uma forma mais dinâmica e coerente com as transformações e demandas educacionais. Os participantes puderam vivenciar e entender que o Facebook, pode ir além de um espaço de entretenimento, constituindo-se também como um espaço de aprendizagem e formação, que pode fornecer dados importantes que indicam auxílio na construção de novos conhecimentos e no desenvolvimento de uma aula.

Vale considerar ainda que ficou evidente o potencial de acessibilidade que a rede social Facebook pode proporcionar. Nesse sentido, os participantes reconheceram que essa rede é relevante para o aprendizado de todos os indivíduos, indistintamente. Eles compreenderam ainda o Facebook como um espaço diversificado de aprendizagem e de fácil manuseio, ficando claro assim que pode haver sim, aprendizagem por meio dessa rede social, pois as pessoas estão boa parte do dia conectadas a esse ambiente virtual. Fato esse que contribuiu com a aprendizagem e o compartilhamento dos conteúdos no grupo do curso de Libras, tornando-os acessiveis. O Facebook, é uma poderosa ferramenta de comunicação amplamente aceita e utilizada pela sociedade, sendo assim, pode-se pensar em diferentes formas de utilizá-lo no campo educacional e em prol de uma educação inclusiva, por sua larga escala.

Verificou-se assim que, o Facebook é um espaço que favorece a aprendizagem nos dias atuais, e que os alunos podem, por meio dele, interagir com diferentes grupos de estudos, nas mais diferentes áreas e aprender de forma colaborativa, mobilizando e desenvolvendo diversas competências e habilidades. De acordo com Moran (2012), sobre a competência de professores e alunos, em saberem conviver e relacionarem-se nos diferentes espaços virtuais e digitais:

Uma nova competência que precisa ser desenvolvida hoje é a de saber conviver nos espaços virtuais, saber comportar-se na comunicação on-line, nos diversos espaços digitais pelos quais nos movemos, 
Formação docente e o ensino de Libras...

respeitar a diversidade, comentar com equilíbrio opiniões diferentes ao divulgar informações sobre terceiros (MORAN, 2012, p. 67).

Portanto, é necessário que os professores sejam formados e orientados a adquirir e aplicar tais competências, pois serão eles que orientarão os alunos no variado uso dos espaços e redes sociais virtuais, de forma ética, assegurando o intercâmbio de ideias, informações e conhecimentos. Com isso, o professor precisa estar aberto a esse espaço colaborativo de construção de conhecimentos, reconhecendo seus recursos e sua articulação com práticas pedagógicas adequadas, com o objetivo de reestruturar e alavancar os processos de ensino e aprendizagem inclusiva, compreendendo e oportunizando a cultura digital em suas estratégias didático-metodológicas, entendendo as necessidades e estilos de aprendizagem dos alunos, considerando as especificidades do século XXI.

\section{Referências}

BARANAUSKAS, M. C. C.; MARTINS, M. C.; VALENTE, J. A. (Orgs). Codesign de redes digitais: tecnologia e educação a serviço da inclusão social. Porto Alegre: Penso, 2013.

GOLDFELD, M. A criança surda: linguagem e cognição numa perspectiva sociointeracionista. 2. ed. São Paulo: Plexus, 2002.

MINAYO, M. C. S. Ciência, técnica e arte: o desafio da pesquisa social. In: MINAYO, M. C. S. (Org.). Pesquisa social: teoria, método e criatividade. Petrópolis, RJ: Vozes, 2001. p. 9-29.

MORAN, J. M. A educação que desejamos: novos desafios e como chegar lá. 5. ed. Campinas, SP: Papirus, 2012.

MORAN, J. M.; MASETTO, M. T.; BEHRENS, M. A. Novas tecnologias e mediação pedagógica. Campinas, SP: Papirus, 2000. 
Raquel Rosan Christino Gitahy, Adriana Aparecida De Lima Terçariol e Mariane Della Coletta Savioli

NÓVOA, A. História da profissão docente: desafios para a pesquisa. Palestra proferida na PUC - Rio em 25 de agosto de 1998.

PIMENTA, S. G.; GHEDIN, E. (Orgs.). Professor reflexivo no Brasil: gênese e crítica de um conceito. 4. ed. São Paulo: Cortez, 2006.

PIMENTEL, M. G. O professor em construção. 3. ed. Campinas, SP: Papirus, 1996.

QUADROS, R. M. de; KARNOPP, L. Lingua de sinais brasileira: estudos lingüísticos. Porto Alegre: Porto Artmed, 2004

VAlENTE, J. A.; PRADO, M. E. B.; ALMEIDA, M. E. B. (Orgs.). Educação a distância via Internet. São Paulo: Avercamp, 2003.

VASCONCELlos, C. dos S. Para onde vai o Professor? Resgate do Professor como Sujeito de Transformação. São Paulo: Libertad, 1996. 